\section{On: Hall S, Lewith G, Brien S, Little P: A review of the literature in applied and specialised kinesiology. Forsch Komplementmed 2008;15:40-46.}

\author{
Key Words \\ Applied Kinesiology · Muscle testing · Kinesiology · \\ Touch for Health
}

\section{Summary}

We commend the authors for attempting an in-depth literature review of such a diverse field as Specialised Kinesiology. Their recommendations for the tools that can be used in methods of analysis in future studies are well advised. The title of their paper, however, suffers from design flaws and is deceptive. This paper is primarily a review of Touch for Health Kinesiology and its family of techniques, which should be distinctly differentiated from Applied Kinesiology as defined by the International College of Applied Kinesiology.

The authors should be commended for attempting an in-depth literature review of such a diverse field as Specialised Kinesiology [1]. Their recommendations for the tools that can be used in methods of analysis in future studies are well advised. The title of their paper, however, is deceptive. This paper is primarily a review of Touch for Health Kinesiology and its family of techniques, which should be distinctly differentiated from Applied Kinesiology (AK) as defined by the International College of Applied Kinesiology (ICAK) [2].

The term 'Specialised Kinesiology' used in this paper appears to refer to the various adaptations of Touch for Health Kinesiology rather than the licensed-to-diagnose physicians who use AK. Any member of the public can receive Touch for Health training. However, only doctors licensed to diagnose may receive training in AK. These groups include chiropractors, osteopaths, general medical practitioners, dentists, psychiatrists and other mainstream providers [3].

The inclusion criteria of the reviewed literature in this paper specifically excluded most of the professional research literature relevant to $\mathrm{AK}$, because the AK methods of manual muscle testing (MMT) did not meet their definition of kinesiology practice. This should have eliminated the application of the author's conclusions to AK; however, they were not so cautious. They assert that because the literature does not support the 'Kinesiology' methods they limited their literature review to, the literature does not support the AK methods on which these other 'Kinesiologies' are founded.

The operational definition of the MMT used by physical therapists, neurologists, and orthopedists is the same as that used by chiropractors who use the standardized MMT methods taught in AK.

How can these authors assert that their review of the MMT literature is adequate, when they have excluded from consideration the research of the founders of this system of testing? Goodheart never altered the methodology of the MMT that came from the original work of Kendall and Kendall [4-5]. The standard references for muscle testing evaluation as accepted by the ICAK are the original work of Kendall and Kendall 'Muscles: Testing and Function', and the modifications suggested by Goodheart in his 'Applied Kinesiology Research Manuals'. The ICAK, in teaching MMT methods to licensed healthcare professionals, has always used the methods of the Kendalls.

The Kendall, and by association the AK system of testing has now been accepted by the American Medical Association as a reliable and valid method for evaluating functional, nonpathological, radicular, and non-radicular neuromusculoskeletal conditions [6].

None of the literature supporting these methods was included in this article's review. In fact the authors claimed to have searched CINHAL, but completely excluded the MANTIS chiropractic database. Their search failed to cite over 20 research papers in CINAHL on the reliability, concurrent, convergent, discriminant and predictive validity, and clinical outcome studies of the AK MMT method [7]. To ignore all of this research means there is a strong internal bias in this study and that it should probably never have been published.

Excluding Kendall and Kendall's, Goodheart's and the ICAK's criteria for MMT forced the authors to define their own MMT criteria for inclusion in their literature review. This creates the very problem the authors described as 'the lack of available quality criteria tools for inter-examiner reliability studies or muscle response to stimuli studies necessitated us to define our own criteria' (emphasis added). The authors limited their search criteria to the 'light muscle test' which must be the authors' interpretation of Touch for Health's two-finger pressure testing. Then, the authors ask that 'a Delphi or similar consensus establish whether there are real differences

\section{KARGER}

Fax +497614520714

Information@Karger.de

www.karger.com
() 2008 S. Karger GmbH, Freiburg

Accessible online at:

www.karger.com/fok 
which are important for study design' of the different muscle testing systems currently used in the world. Such a validated model for the MMT already exists; and it was this model that they excluded from their review!

The importance of assessing the functional state of the motor system with MMT as taught in AK is emphasized by studies suggesting that faulty motor control is the most likely source of at least $50 \%$ of low back pain syndromes [8].

The evidence now shows with greater clarity than ever before that inflammation or injury produces specifically identified inhibited muscles. Controlled clinical studies have shown that dysfunction and pain specifically in the ankle [9], knee [10-12], lumbar spine [13-15], temporomandibular joint [16], and cervical spine [17-20] will produce inhibited muscles. These data indicate that the body's reaction to injury and pain is not increased muscular tension and stiffness; rather muscle inhibition is often more significant.

Several hundred peer-reviewed studies are available for review at the ICAK websites (that used age- and sex-matched controls) showing that the level of muscle activity is not higher than normal in most of the common musculoskeletal conditions, but reduced [21]. This research literature should have been an essential component of this review of AK and Specialised Kinesiology.

The MMT, when properly taught and executed, gives practitioners the ability to diagnose these causative problems. No other method for detecting muscle weakness exists that has the reliability, the 'face validity' for patients, and the ease of use as the MMT [7].

Dishman et al. [22] have shown this year and in a series of previous studies that spinal manipulative therapy (SMT) leads to an increase in central motor excitability rather than inhibition. Specifically their report and review of the literature shows that there is postsynaptic facilitation of $\alpha$ motoneurons and corticomotoneurons that may be unique to chiropractic SMT.

Previous work by Dishman and others has demonstrated that there is an immediate strengthening effect upon the peripher- al muscles after SMT [23-28]. In the research just cited virtually every condition that chiropractors and other manual therapists face involves some form of muscle inhibition. This is the reason for the necessity of the MMT in manual diagnosis and treatment.

This factor has been consistently demonstrated in AK and other manipulative systems that use the MMT. Manipulative procedures that are specifically designed to improve the function of muscles during daily life should improve spinal function and reduce disability [5,29-31].

The authors confuse their judgment about the professional use of AK by entangling it with the 'Specialised Kinesiologies' and 'energy kinesiologies' of the Touch for Health offshoots. As they explain, Dr. John Thie (a chiropractor) developed a simple offshoot of the chiropractic AK work that could be taught to the public and his patients in weekend seminars. Many of the methods the authors describe as 'Specialised Kinesiology' (which have nothing whatever to do with AK) even diverge dramatically from Thie's original home health program such as astrological kinesiology [32]. While these specialised kinesiologies may be similar in their divergence, they have little resemblance to their parent model of Touch for Health or to their root model of AK and therefore should not be confused with AK in this way.

The authors conclude that because there is insufficient research evidence for Touch for Health, there is also insufficient research evidence for AK methods. This is presumptuous and completely insupportable [7,21]. The sweeping statement that 'there is insufficient evidence that kinesiology (of any type) has any specific therapeutic effect for any condition' may apply to the offshoots of Touch for Health and energy kinesiologies (the focus of their study), and should not include the methods used by physicians licensed to diagnose who use AK MMT.

This study suffers from significant design flaws that make its applicability to the community of physicians who use the standardized MMT taught in the chiropractic and other manual medical colleges insupportable.

Donald McDowall, Belconnen, ACT Scott Cuthbert, Pueblo, CO

\section{References}

$\checkmark 1$ Hall S, Lewith G, Brien S, Little P: A Review of the literature in applied and specialised kinesiology. Forsch Komplementmed 2008;15:40-46.

2 www.icak.com/college/status.shtml (accessed Oct 5, 2008).

3 www.icak.com/about/chapterreports2007.shtml (accessed Oct 5, 2008).

4 Kendall FP, McCreary EK, Provance PG: Muscles: Testing and Function. Baltimore, MD, Williams and Wilkins, 1993.

5 Goodheart GJ: Applied Kinesiology Research Manuals. Detroit, MI, privately published yearly, 1964-1995.

6 American Medical Association: Guides to the Evaluation of Permanent Impairment, ed 5. 2001, p 510
7 Cuthbert SC, Goodheart GJ Jr: On the reliability and validity of manual muscle testing: a literature review, Chiropr Osteopat 2007;15:4.

8 Mannion AF, Junge A, Taimela S, Müntener M, Lorenzo K, Dvorak J: Active therapy for chronic low back pain: part 3. Factors influencing self-rated disability and its change following therapy. Spine 2001;26:920-9.

9 Nicholas JA, Marino M: The relationship of injuries of the leg, foot, and ankle to proximal thigh strength in athletes. Foot Ankle 1987;7:218-28.

10 Slemenda C, Brandt KD, Heilman DK, Mazzuca S, Braunstein EM, Katz BP, Wolinsky FD: Quadriceps weakness and osteoarthritis of the knee. Ann Intern Med 1997;127:97-104.
11 Stokes M, Young A: Investigations of quadriceps inhibition: implications for clinical practice. Physiotherapy 1984;70:425-428.

12 Spencer JD, Hayes KC, Alexander IJ: Knee joint effusion and quadriceps reflex inhibition in man. Arch Phys Med Rehab 1984;65:171-177.

13 Nummi J, Jarvinen T, Stambej U, Wickstrom G: Diminished dynamic performance capacity of back and abdominal muscles in concrete reinforcement workers. Scand J Work Environ Health 1978;4 (suppl 1):39-46.

14 Hodges PW, Richardson CA: Inefficient muscular stabilization of the lumbar spine associated with low back pain. Spine 1996;21:2640-2650. 
15 Hossain M, Nokes LDM: A model of dynamic sacro-iliac joint instability from malrecruitment of gluteus maximus and biceps femoris muscles resulting in low back pain. Med Hypotheses 2005;65: 278-281.

16 Zafar H: Integrated jaw and neck function in man. Studies of mandibular and head-neck movements during jaw opening-closing tasks. Swed Dent J Suppl 2000;143:1-41.

17 Jull GA: Deep cervical flexor muscle dysfunction in whiplash. J Musculoskel Pain 2000;8:143-154.

18 Jull G, Barret C, Magee R, Ho P: Further clinical clarification of the muscle dysfunction in cervical headache. Cephalgia 1999;19:179-185.

19 Vernon HT, Aker P, Aramenko M, Battershill D, Alepin A, Penner T: Evaluation of neck muscle strength with a modified sphygmomanometer dynamometer: reliability and validity. J Manipulative Physiol Ther 1992;15:343-9.

20 Edgerton VR, Wolf SL, Levendowski DJ, Roy RR: Theoretical basis for patterning EMG amplitudes to assess muscle dysfunction. Med Sci Sp Exer 1996;28:744-751.
21 ICAK-USA and ICAK-International websites: AK Research Compendium. Dr. Scott Cuthbert, 9-162007. www.icakusa.com/scientificresearch.php and www.icak.com/college/research/publishedarticles.sh tml (accessed Oct 5, 2008).

22 Dishman JD, Greco DS, Burke JR: Motor-evoked potentials recorded from lumbar erector spinae muscles: a study of corticospinal excitability changes associated with spinal manipulation. J Manipulative Physiol Ther 2008;31(4):258-70.

23 Shambaugh P: Changes in electrical activity in muscles resulting from chiropractic adjustment: a pilot study. J Manipulative Physiol Ther 1987;10:300304.

24 Dishman JD, Bulbulian R: Spinal reflex attenuation associated with spinal manipulation. Spine 2000;25: 2519-25.

25 Suter E, McMorland G: Decrease in elbow flexor inhibition after cervical spine manipulation in patients with chronic neck pain. Clin Biomech (Bristol, Avon) 2002;17:541-4.
26 Floman Y, Liram N, Gilai AN: Spinal manipulation results in immediate H-reflex changes in patients with unilateral disc herniations. Eur Spine J 1997;6: 398-401.

27 Unger J: The effects of a pelvic blocking procedure upon muscle strength: a pilot study. Chiropr Tech 1998;10:150-155.

28 Perot D, Goubel F, Meldener R: Quantification of the inhibition of muscular strength following the application of a chiropractic maneuver. Journale de Biophysique et de Biomecanique 1986;32:471-474.

29 Lewit K: Manipulative Therapy in Rehabilitation of the Locomotor System, ed 3. London, Butterworths, 1999.

30 Liebenson C (ed): Rehabilitation of the Spine: A Practitioner's Manual, ed 2. Lippincott, PA, Williams und Wilkins, 2007.

31 Janda V: Muscle Function Testing. London, Butterworths, 1983.

32 kinesiologycollege.com.au/index.php/Courses/ Short-Courses/Astro-Kinesiology.html (accessed Oct 5, 2008). 